Check for updates

Cite this: RSC Adv., 2017, 7, 53778

Received 26th September 2017 Accepted 14th November 2017

DOI: 10.1039/c7ra10662a

rsc.li/rsc-advances

\section{Sensitive profiling of trace neurotoxin domoic acid by pressurized capillary electrochromatography with laser-induced fluorescence detection $\uparrow$}

\begin{abstract}
Qingai Chen, ${ }^{a}$ Lijun Deng, ${ }^{\mathrm{b}}$ Jinxin Chi, ${ }^{\mathrm{b}}$ Min Liu, ${ }^{\mathrm{b}}$ Xucong Lin (D) ${ }^{* \mathrm{~b}}$ and Zenghong Xie ${ }^{\mathrm{b}}$
A stable, sensitive and low-reagent consumption method for the quantification of trace neurotoxin domoic acid (DA) was presented by pressurized capillary electrochromatography (pCEC) with laser-induced fluorescence (LIF) detection. Migration behaviours of DA were studied under different separation modes such as PCEC and capillary HPLC. Separation parameters including the mobile phase, applied voltage, supplementary pressure and sample loading rate were investigated. Double modes including electrophoretic migration and chromatographic retention were employed and an efficient separation of DA was achieved with a flow of $1.2 \mu \mathrm{L} \mathrm{min}{ }^{-1}$ in a capillary column. Sensitive analysis of DA was achieved with a detection limit of DA in shellfish tissue extracts as low as $10 \mathrm{ng} \mathrm{mL}^{-1}$ (equivalent to $15 \mathrm{ng}$ DA per g, wet weight). The stability and repeatability of pCEC-LIF was evaluated and a good result was gained with RSDs $(n=3)$ for the retention time and peak area of DA less than $0.5 \%$ and $2.0 \%$, respectively. Applied to shellfish samples, the recoveries were satisfactory and the variation of the quantification of DA was acceptable when compared with the HPLC-MS/MS method.
\end{abstract}

\section{Introduction}

Domoic acid (DA), the principal causative toxin of amnesic shellfish poisoning (ASP), is produced by the algae pseudonitzschia and could accumulate in the edible tissue of shellfish. ${ }^{1,2}$ Consuming the contaminated shellfish seafoods could cause severe neurological symptoms such as memory loss, headaches, loss of balance, nausea, etc. ${ }^{3}$ Marine animals and even human beings will exhibit acute intoxication after consumption of these contaminated foods. Fabricating a facile and sensitive method to monitor trace DA is important and is attracting more and more attention.

Commonly, HPLC with UV detection has been widely utilized for quantifying DA in shellfish. ${ }^{4}$ By means of fluorescence detection (FLD) with pre-column or post-column derivatization, the HPLC-FLD method is often used with a low detection limit for trace analysis of DA. ${ }^{5-7}$ HPLC with MS detection including LC-MS/ MS, LC-laser ablation ESI-MS and SPE-LC-MS/MS, have also been developed for the detection of DA. ${ }^{\mathbf{8 - 1 0}}$ These methods are stable, efficient and sensitive, however, a considerable amount of organic elution solution is consumed and consequently these methodologies might be unfavourable for economical and environment-friendly applications to a certain degree.

${ }^{a}$ Department of Tourism, Fujian Business University, P. R. China

${ }^{b}$ Institute of Food Safety and Environmental Monitoring, Fuzhou University, P. R. China.E-mail:xulin@fzu.edu.cn

$\dagger$ Electronic supplementary information (ESI) available. See DOI: 10.1039/c7ra10662a
As the effective microfluid separation technology, capillary electrophoresis (CE) and capillary electrochromatography (CEC) have been proposed. Fast analysis of DA using microchip electrophoresis with laser-induced fluorescence (LIF) detection has been proposed. ${ }^{11} \mathrm{CEC}$ coupling a high voltage to induce electroosmotic flow (EOF) with a capillary LC column has been formed for the analysis of ASP toxins. ${ }^{12,13 a}$ Leaó Martins et al. firstly developed a CEC method for the analysis of DA. ${ }^{12}$ A. GagoMartínez et al. reported the detection of DA with the combination of CEC and photodiode array detection (PAD). ${ }^{13} \mathrm{CE}$ and CEC have been studied and applied to algae toxins. However, the primary problem in CE or CEC was associated with bubble formation produced by Joule heating as a result of the electric current passing through the column. ${ }^{13}$ The bubbles generate baseline noise and make it difficult to obtain stable flow conditions. Besides, by using electrokinetic injection, quantitative sample introduction was achieved in CE or CEC for the DA analysis, but it might be influenced by the conductivity of sample matrix. The main drawback associated with CE or CEC is the lack of adequate robustness and reproducibility. ${ }^{\mathbf{1 3 , 1 4}}$

To address these problems mentioned above, pressurized capillary electrochromatography (pCEC) has been proposed by coupling an HPLC pump onto the inlet end of the capillary to provide auxiliary pressure to flush capillary column with solvent and inhibit bubble formation. ${ }^{\mathbf{1 3 a}, \boldsymbol{b}}$ Quantitative sample injection could be facilely achieved through a reliable rotary-type injector in pCEC system. In pCEC, both high efficiency of CEC and high selectivity of HPLC were successfully combined. ${ }^{15-17}$ The mobile phase is driven by both hydraulic pressure and electroosmotic 
flow (EOF), and resulted in an efficient elution and the questions such as bubble formation and unstable quantitation could be effectively solved. ${ }^{18-20}$ By superimposing a hydraulic pressure onto the electrically generated flow in capillary column, double modes that are electronic interaction and chromatographic retention could be employed for the efficient separation with a high resolution. ${ }^{18,19}$ Furthermore, the mobile solution as low as nano-litre flow level in capillary column could be carried out facilely in pCEC. It is desirable and become an attractive alternative to common HPLC and pure CEC for the robust and effective analysis.

To date, with the popular UV detection, pCEC-UV method has been used to rapid quantify of DA in shellfish seafood with a determination limit equivalent to $2.0 \mu \mathrm{g}$ DA per $\mathrm{g} .{ }^{21}$ It always suffers from low detection sensitivity due to a rather short optical path length in capillary column for on-line photometric detection. To gain a high sensitivity, laser induced fluorescence detection (LIF) that is well suitable for capillary microseparation with a strong laser to overcome the limit of optical path length in capillary column could be utilized. Ultratrace levels of detection limit $\left(10^{-11} \mathrm{~mol} \mathrm{~L}{ }^{-1}\right.$ levels for fluorescein) were achieved with LIF and presented an obvious advantage over common UV detection. ${ }^{22}$ Since introduced firstly by Yan et al. in $1995,{ }^{23}$ capillary electrochromatography with LIF methods have attracted close attentions in trace detection of polycyclic aromatic hydrocarbons, ${ }^{23}$ aflatoxins, ${ }^{24}$ flavins in plasma ${ }^{25}$ or proteins. ${ }^{26}$ So far, pCEC-LIF method for the trace detection of non-protein amino acids toxin DA has still not reported and its utilization will provide an attractive way for the low-reagent consumption and sensitive analysis of ASP.

Here, we present the development and application of the pCEC-LIF method for the quantification of trace DA in shellfish tissue extracts. Migration behaviours of DA were studied under different separation modes including pCEC and capillary HPLC. A series of parameters including mobile phase, applied voltage, hydraulic pressure and sample loading rate were investigated for optimum electrochromatography behaviour. The stability and reproducibility of pCEC-LIF method were evaluated, as well as the detection limit of DA. The recoveries of shellfishes samples spiked with DA were analyzed, and the method validation in detection results was finally evaluated by comparing with the authoritative HPLC-MS/MS method.

\section{Experimental}

\subsection{Instrumentation}

pCEC was performed on pCEC system (Trisep ${ }^{\mathrm{TM}} 2100 \mathrm{GV}$, Unimicro Technologies, USA), which consisted of a solvent delivery gradient module, a micro-fluid manipulation module (including a $0.8 \mu \mathrm{L}$ six-port injection valve, a four-port split valve, and a back-pressure regulator), a high voltage power supply $(0- \pm 30 \mathrm{kV})$, a data acquisition module, and a LD-DPSS LIF detector $\left(10 \mathrm{~mW}, \lambda_{\mathrm{ex}}=473 \mathrm{~nm} ; \lambda_{\mathrm{em}}=530 \mathrm{~nm}\right)$. Samples are injected to sample loop and then carried to four-port split valve by mobile phase. Under a constant pressure, the total flow from four-port valve was split and a nano-flow was driven into capillary column with a split device. Applied voltage was imposed at the outlet end of column, and the inlet end was connected to the four-port split valve and grounded. HPLC-MS/ MS system and the program were shown in ESI. $\dagger$

\subsection{Reagents and materials}

Domoic acid standard ( $\geq 97 \%$, HPLC-grade) was purchased from Sigma-Aldrich (USA), 4-fluoro-7-nitrobenzo-2-oxa-1,3diazole (NBD-F) ( $\geq 98 \%$, HPLC-grade) was purchased from TCI (Japan), HPLC-grade acetonitrile and methanol were purchased from Chemical Reagent Corp (Shanghai, China), the other chemicals were analytical grade. A packed capillary column $(100 \mu \mathrm{m} / \mathrm{id} .375 \mu \mathrm{m} / \mathrm{od}$., total length $55 \mathrm{~cm}$, of which $20 \mathrm{~cm}$ was packed with $3 \mu \mathrm{m}$ octadecyl silica (ODS) particles) was obtained from Global Chromatography (SuZhou, China). Sep-Pak SAX (3 mL, $200 \mathrm{mg}$ ) SPE columns were purchased from Waters (Milford, MA, USA). Deionized water was prepared with a Milli-Q water purification system (Milford, MA, USA).

\subsection{Sample preparation}

The procedure for handling shellfish tissue was based on the previous ref. 6 and 21. Approximately $50 \mathrm{~g}$ of shellfish tissue was homogenized with the blender. A $4.0 \mathrm{~g}$ homogenated tissue was used and extracted with $15.0 \mathrm{~mL}$ extraction solvent $(1: 1$ methanol-water) and homogenized again for $3 \mathrm{~min}$ at $13000 \mathrm{rpm}$. The resulting slurry was then centrifuged at $4000 \mathrm{rpm}$ for $10 \mathrm{~min}$, and the centrifuged sample was then filtered through a $0.22 \mu \mathrm{m}$ membrane and was purified further using the following SPE procedure according to the work reported by M. Maroulis et al. ${ }^{6}$

A $5.0 \mathrm{~mL}$ fraction of the filtered crude extract was loaded onto the cartridge in a flow rate of about one drop per second. The cartridge was washed at about one drop per second with $5 \mathrm{~mL}$ wash solution (acetonitrile-water $=10: 90, \mathrm{v} / \mathrm{v}$ ). Then the effluent was discarded and $0.5 \mathrm{~mL}$ of $0.1 \mathrm{~mol} \mathrm{~L}^{-1}$ formic buffer eluent ( $\mathrm{pH} 2.92 \pm 0.01$, adjusted with sodium hydroxide) was added. The effluent was discarded again. The formic buffer $\left(0.1 \mathrm{~mol} \mathrm{~L}^{-1}\right)$ were loaded onto the cartridge and allowed to flow at a rate of one drop per second. Exactly $2.0 \mathrm{~mL}$ of the final eluted DA extract were collected for further analysis.

\subsection{Derivatization of domoic acid with NBD-F}

According the ref. 8, NBD-F in acetonitrile $\left(1.0 \mathrm{mg} \mathrm{mL}^{-1}, 50 \mu \mathrm{L}\right)$ and $0.10 \mathrm{~mol} \mathrm{~L}^{-1}$ sodium borate $(50 \mu \mathrm{L})$ were mixed with sample extract or standard solution $(50 \mu \mathrm{L})$ in an amber vial $(2 \mathrm{~mL})$, at $20{ }^{\circ} \mathrm{C}$ and the reaction was terminated after $3 \mathrm{~min}$ by adding $1.0 \mathrm{~mol} \mathrm{~L}^{-1} \mathrm{HCl}(50 \mu \mathrm{L})$ to the mixture. An aliquot of this derivatised mixture was analysed directly by pCEC-LIF.

\section{5 pCEC-LIF procedure}

Mobile phase was composed of phosphate buffer solution and ACN with the appropriate concentration and desired $\mathrm{pH}$ value. The $\mathrm{pH}$ values and salt concentrations mentioned in this work were that of phosphate buffer solution.

By using acetonitrile-phosphate buffer solution (60:40, v/v) as mobile phase, isocratic pressurized electrochromatography 
was performed with a octadecyl silica (ODS) packed capillary column mentioned above. A supplementary pressure (7.2 MPa) was applied to the column inlet and the nano-flow was driven by the pump with a split ratio of 1/15. Before conducting pCEC experiments, capillary column was conditioned with mobile phase for $30 \mathrm{~min}$ and the column was kept at $25^{\circ} \mathrm{C}$. The applied voltage was ramped from 0 to $+8 \mathrm{kV}$ at first and then maintained at $+6 \mathrm{kV}$. Fluorimetric detection was used $\left(\lambda_{\mathrm{ex}}=473 \mathrm{~nm} ; \lambda_{\mathrm{em}}=530 \mathrm{~nm}\right)$.

\subsection{Method validation}

The method was evaluated and validated through linearity, limit of detection (LOD), fortified recoveries and precision, and the program was shown in ESI. $\dagger$ Precision of the method was evaluated by the intra-day and inter-day RSD. The intra-day RSD was obtained from analysing five replicates of the sample spiked with $0.25 \mu \mathrm{g} \mathrm{mL}^{-1}$ of DA on the same day, and the interday RSDs were determined by analysing the sample based on five replicates on three consecutive days. The comparison with the authoritative HPLC-MS/MS method was carried out to further evaluate the feasibility of this method.

\section{Results and discussion}

\section{1 pCEC mode for DA detection}

In pCEC, an HPLC pump to superimpose a hydraulic pressure at the inlet of capillary column onto an electrically generated flow. Mobile phase is driven by both EOF and pressurized flow, and the linear velocity of a charged solute in mobile phase $\left(u_{\mathrm{m}}\right)$ is the sum of the velocities contributed from electrophoretic migration velocity $\left(u_{\mathrm{em}}\right)$, pressurized flow $\left(u_{\mathrm{p}}\right)$, and EOF $\left(u_{\mathrm{eo}}\right)$. As shown in Fig. 1, double driving forces including a hydraulic pressure and an electroosmotic flow (EOF) could be employed and double modes including electrophoretic migration (EM) between the electrode and charged solutes and capillary micro-liquid chromatographic ( $\mu$-HPLC) retention of packed stationary phase could be employed for the separation of DA derivatization products.

To evaluate the chromatographic behaviour of DA derivatization product DA-NBD, DA standard solutions and shellfish tissue extracts spiked with DA were used and the results were shown in Fig. 2 and 3. In Fig. 2, the migration time of DA-NBD was shortened to $12 \mathrm{~min}$ in PCEC with a positive high voltage of
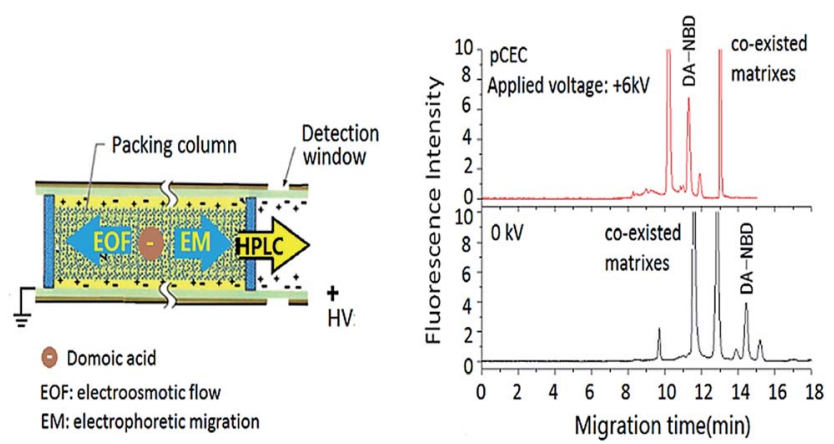

Fig. 1 Scheme of multiple separation interactions in PCEC for DA detection.

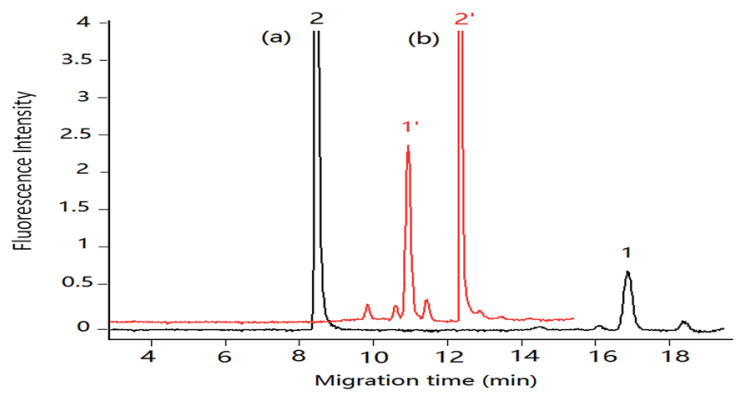

Fig. 2 Migration of DA in PCEC with negative and positive applied voltage respectively. Mobile phase, $60 \%(\mathrm{v} / \mathrm{v})$ acetonitrile, $40 \%(\mathrm{v} / \mathrm{v})$ of $5.0 \mathrm{mmol} \mathrm{L}^{-1}$ phosphate buffer $(\mathrm{pH} 2.5)$, supplementary pressure 1000

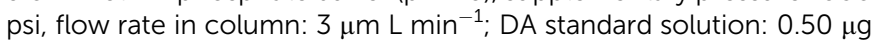
$\mathrm{mL}^{-1}$. Applied voltage: (a) $-6 \mathrm{kV}$, (b) $+6 \mathrm{kV}$. Peak 1 and $1^{\prime}:$ DA-NBD, 2 and $2^{\prime}$ : NBD-F hydrolysis products.

$+6 \mathrm{kV}$, while prolonged to more than 16 min when a negative high voltage $-6 \mathrm{kV}$ was applied. It indicated that DA-NBD was of negatively charge and the electrophoresis action could enhance the migration rate and the fluorescence response of DA-NBD remarkably, which was in favour of the rapid and sensitive analysis of trace DA. By using a positive high voltage, the migration rate of DA-NBD was accelerated obviously benefitting from electrophoretic migration with the same direction of hydraulic pressure though the cathode EOF was in the oppose direction. In pCEC, the electrophoretic migration and electroosmotic flow were of importance for the migration and effective separation of DA.

Compared with the $\mu$-HPLC method which achieved under the same experimental conditions as that of pCEC method except applied voltage, a higher sensitivity and a rapid elution of DA were obtained (shown in Fig. 3). Applied to shellfish tissue extracts, the pCEC-LIF method was suitable for DA detection. The separation of DA-NBD and co-eluted matrixes were successfully achieved with a high sensitivity.

\subsection{Optimization of separation parameters}

3.2.1 Effect of $\mathbf{p H}$ of buffer solution. The $\mathrm{pH}$ value mentioned in this case was that of phosphate buffer solution. DA has three carboxyl groups and a secondary amine, and the
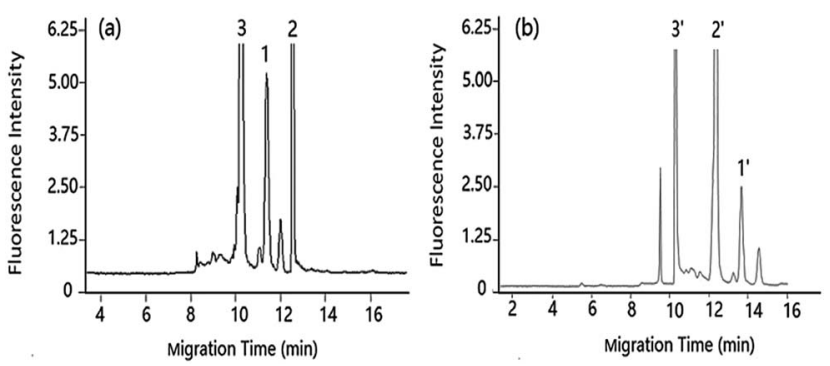

Fig. 3 Separation of DA under PCEC and CLC in shellfish tissue extracts shellfish tissue extracts spiked with DA: $1.00 \mu \mathrm{g} \mathrm{mL}^{-1}$. Applied voltage: (a) $+6 \mathrm{kV}$, (b) $0 \mathrm{kV}$. Other conditions as Fig. 2. Peak 1 and 1': DA-NBD, 2 and 2': NBD-F hydrolysis products, 3 and $3^{\prime}$ : co-eluted compounds. 


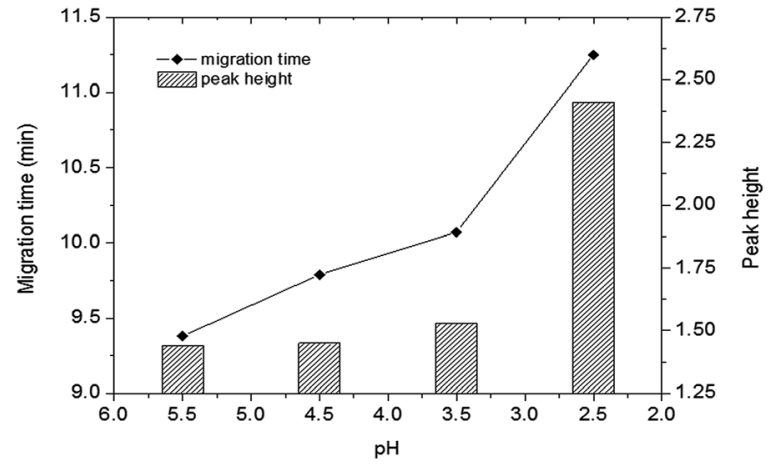

Fig. 4 Effect of pH on the detection of DA in shellfish tissue extracts. Mobile phase, $60 \%(\mathrm{v} / \mathrm{v})$ acetonitrile, $40 \%(\mathrm{v} / \mathrm{v})$ of $5 \mathrm{mmol} \mathrm{L}^{-1}$ phosphate buffer, applied voltage: $+6 \mathrm{kV}$; supplementary pressure: 1000 psi. Other conditions as Fig. 2. DA: $0.50 \mu \mathrm{g} \mathrm{mL}^{-1}$.

$\mathrm{pH}$ of mobile phase has an obvious influence on its chromatographic retention and electronic interactions. In this case, the migration of neutral NBD-F was drove by hydraulic pressure and electroosmotic flow (EOF), and then was studied to evaluate the change of EOF. As shown in Fig. S3, $\dagger$ a little change of migration time occurred at $\mathrm{pH} 5.50-3.50$ while a notable decrease was observed with $\mathrm{pH}$ increasing from 3.50 to 2.50, which indicated that the EOF decreased at $\mathrm{pH}$ 2.50. Interestingly, in Fig. 4, the retention and fluorescence response of DA derivation product (DA-NBD) increase with the $\mathrm{pH}$ decreasing from 5.50 to 3.50 , which was owing to the comprehensive action of the stable EOF in capillary column and the decreasing electrophoretic mobility (with an opposite direction to EOF). At pH 2.50 , the deprotonation of three carboxyl groups and

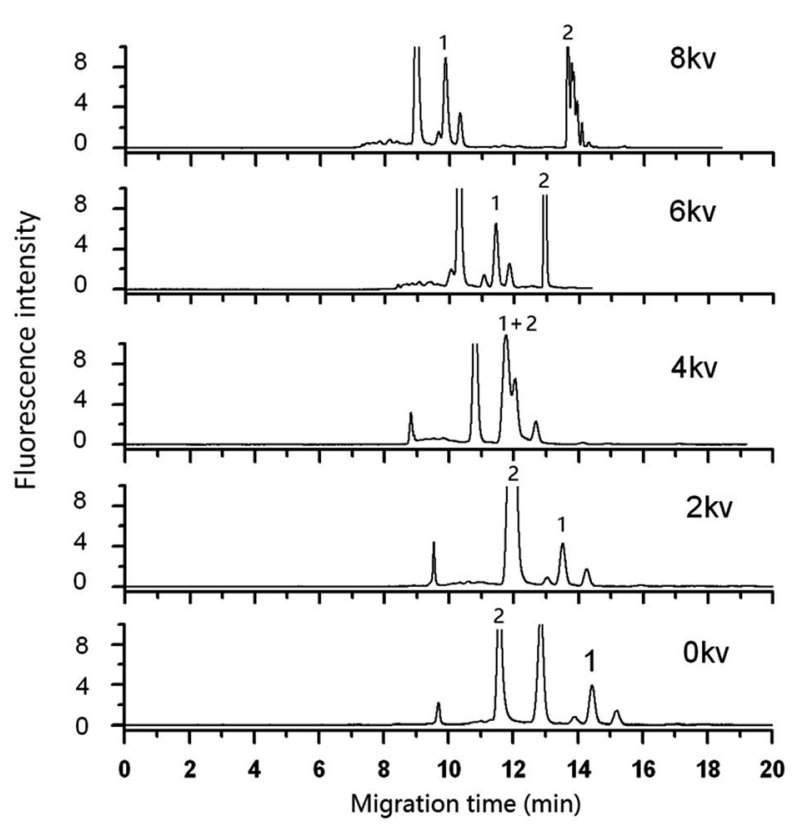

Fig. 5 Effect of applied voltage on the separation of DA in shellfish tissue extracts. Mobile phase, $60 \%(\mathrm{v} / \mathrm{v})$ acetonitrile, $40 \%(\mathrm{v} / \mathrm{v})$ of $5.0 \mathrm{mmol} \mathrm{L}{ }^{-1}$ phosphate buffer solution $(\mathrm{pH} \mathrm{2.5)}$; other as in figure. Peak 1: DA-NBD, 2: NBD-F hydrolysis compounds. protonation of secondary amine in DA was in the highest level. So the net negative charge of DA-NBD was inhibited and thus electrophoretic migration of DA-NBD rapidly reduced. The vector sum of electrophoresis and EOF migration was in the opposite direction of hydraulic pressure, which was helpful to enhance the retention and band compression of DA-NBD in the column. As seen from Fig. 4, both migration time and fluorescence intensity of DA-NBD reached the maximum at $\mathrm{pH} 2.50$, which was favourable to seek a high sensitivity.

3.2.2 Effect of acetonitrile. The content of acetonitrile in mobile phase is a fundamental factor that could affect both the velocity of EOF and chromatographic retention. A high content of acetonitrile could cause an increase in electroosmotic mobility and a stronger elution in the reverse phase chromatography. As seen from Fig. S4, $\uparrow$ an obvious decrease of the retention of DA-NBD and NBD-F hydrolysis products could be observed while the ACN content increased from 55\% to $70 \%$. With the ACN content of $70 \%$, DA-NBD was eluted too fast and mixed with the co-existed substances together. While the ACN content got down to $55 \%$, the retention of DA-NBD was intense and the migration was slow, which resulted in an overlap of DANBD and another co-existed substances. If the ACN content was of $60 \%$, a good separation of DA-NBD and co-eluted compounds could be well achieved with an appropriate retention time.

3.2.3 Effect of buffer concentration. The influence of ionic strength in mobile phase on the separation of DA-NBD was also studied. Generally, the increase of buffer concentration will reduce the EOF of separation column. In Fig. S5, $\uparrow$ the retention time of charged DA-NBD decreased slightly when buffer concentration increased from $2.50 \mathrm{mmol} \mathrm{L}^{-1}$ to $7.50 \mathrm{mmol} \mathrm{L}^{-1}$. The increased phosphate buffer concentration in mobile phase

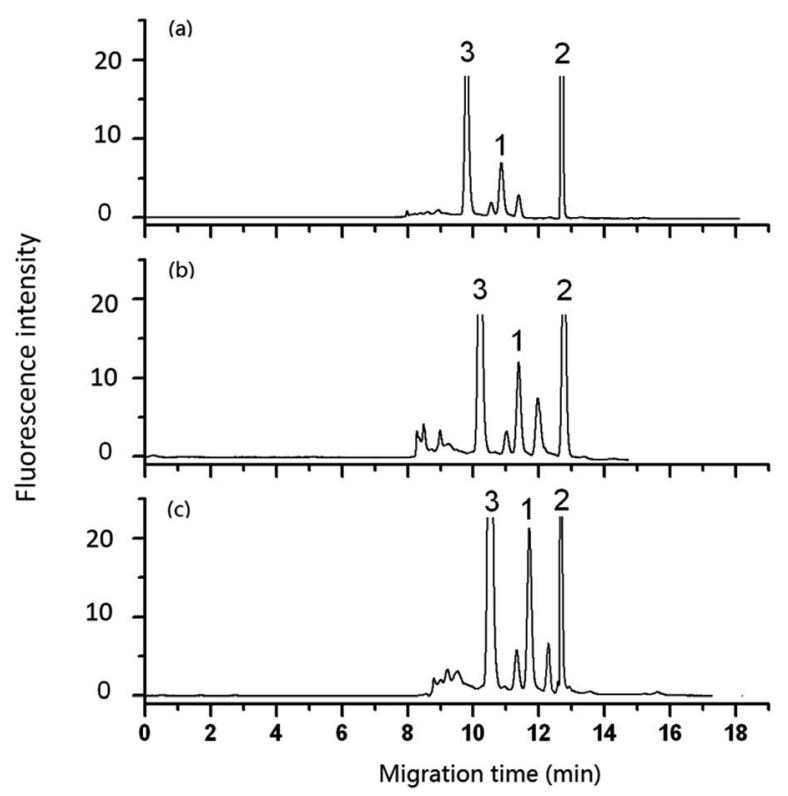

Fig. 6 Effect of flow rate of pump on the analysis of DA in shellfish tissue extracts. Mobile phase, $60 \%(\mathrm{v} / \mathrm{v})$ acetonitrile, $40 \%(\mathrm{v} / \mathrm{v})$ of $5 \mathrm{mmol} \mathrm{L}^{-1}$ phosphate buffer solution ( $\mathrm{pH} 2.5$ ); other conditions as in Fig. 5. Flow rate in column: (a) $3 \mu \mathrm{L} \mathrm{min}^{-1}$, (b) $2 \mu \mathrm{L} \mathrm{min}^{-1}$, (c) $1.2 \mu \mathrm{L} \mathrm{min}^{-1}$. Peak 1: DA-NBD, 2 and 3: co-eluted compounds. 


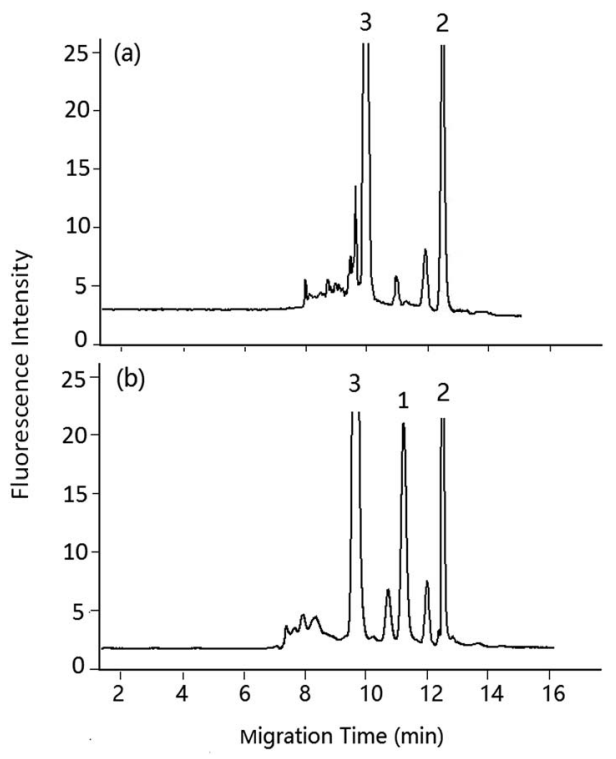

Fig. 7 pCEC analysis of DA in shellfish tissue extracts. Mobile phase, $60 \%(\mathrm{v} / \mathrm{v})$ acetonitrile, $40 \%(\mathrm{v} / \mathrm{v})$ of $5 \mathrm{mmol} \mathrm{L}^{-1}$ PBS buffer $(\mathrm{pH} 2.5)$, applied voltage: $+6 \mathrm{kV}$, supplementary pressure: 1000 psi, spit-flow rate: $1.2 \mu \mathrm{L} \mathrm{min}^{-1}$. (a) Blank sample, (b) spiked with DA standard solution $1.00 \mu \mathrm{g} \mathrm{mL}^{-1}$, peaks: 1: DA-NBD, 2: NBD-F hydrolysis products, 3: co-eluted compounds.

may contribute to the reduction of the EOF on the surface of stationary phase. When the buffer solution with a high concentration of $7.50 \mathrm{mmol} \mathrm{L}^{-1}$ was used, the migration of DANBD could be accelerated, while the migration of neutral NBD-F hydrolysis product was slowed with peak broadening obviously. As a result, the concentration of $5.0 \mathrm{mmol} \mathrm{L}^{-1}$ of PBS buffer solution was selected for the high resolution of DA.

3.2.4 Effect of applied voltage. In Fig. 5, the $\mu$-HPLC method was used for the separation without the application of voltage. In such a way, DA-NBD could be recognized from the matrix but the sensitivity was lower and retention time was longer than that of pCEC, which was unfavourable to sensitive monitoring of trace shellfish toxin. In pCEC, the increase of electric field could enhance the EOF and alters the electrophoretic migration of the charged substances. In this case, the electrophoretic velocity of DA was faster than the EOF in the opposite direction. With the applied voltage increasing, the migration rate of DA-NBD was enhanced as well as fluorescence response, which attributed to the increase of band compression of DA-NBD controlled by the reverse migration of EOF. For neutral NBD-F hydrolysis products, the migration was prolonged with applied voltage increasing, owing to the obvious increase of the reverse migration of EOF. At high voltage of $+6 \mathrm{kV}$, a favourable resolution of DA-NBD was achieved with a high fluorescence response. If the applied voltage increased further and got up to $+8 \mathrm{kV}$, the higher value of applied voltage could lead to a faster migration rate and cause a peak overlap of DA-NBD and matrix solutes, which resulted in a serious decrease of the resolution of DA.

3.2.5 Effect of pump flow. In pCEC, the valid sample volume injected into capillary column is controlled by splitting ratio of the four port split valve. If keeping hydraulic pressure and the flow-rate constant, the spit-flow was constant. But if the flow rate decreased, the injection samples could stay in the spit valve for a longer time. With the flow rate of pump decreasing, the split-flow of injection solution to waste solution decrease, and the injection volume of samples into capillary column would increase. As seen in Fig. 6, when the applied voltage and hydraulic pressure keep constant, decreasing the flow rate in

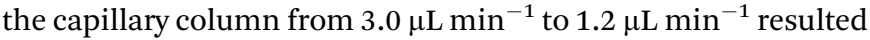
in a remarkable increase in the response of DA-NBD with an acceptable resolution. If the flow rate decreased further and reached $0.6 \mu \mathrm{L} \mathrm{min}{ }^{-1}$, the repeatability of pump flow was poor due to the limitation of HPLC pump. And so a low flow rate of $1.2 \mu \mathrm{L} \mathrm{min}{ }^{-1}$ was selected for the stable and sensitive analysis of DA.

\subsection{Analytical performance}

3.3.1 Calibration curve, detection limit and repeatability. Based on the investigations mentioned above, the optimal conditions were achieved (mobile phase, $60 \% \mathrm{v} / \mathrm{v}$ ACN, $40 \% \mathrm{v} / \mathrm{v}$ of $5 \mathrm{mmol} \mathrm{L}^{-1}$ PBS buffer solution ( $\mathrm{pH} 2.5$ ), supplementary pressure: $1000 \mathrm{psi}$, applied voltage: $+6 \mathrm{kV})$. And then a baseline separation of DA was gained and the co-existed components in the mussel extracts had no obvious influence (Fig. 7). The linearity of the method was determined by constructing a calibration curve with a series of concentrations of DAs in shellfish tissue extracts. As shown in Table 1, the linear range, regression equation, correlation coefficient, and the limit of detection (LOD) are listed. Owing to the high fluorescence yields and stability, the relative standard deviations including inter-day $\operatorname{RSD}(n=5)$ and inter-day RSD $(n=15)$ for retention time and the peak area respectively was acceptable. The LOD of DA was of $10 \mathrm{ng} \mathrm{mL}^{-1}(\mathrm{~S} / \mathrm{N}=3$ ) (equivalent to $15 \mathrm{ng}$ DA per $\mathrm{g}$, w.w. of

Table 1 Parameters for quantification of DA in shellfish tissue extracts

\begin{tabular}{|c|c|c|c|c|c|c|c|c|}
\hline \multirow[b]{2}{*}{ Analytes } & \multirow[b]{2}{*}{$\begin{array}{l}\text { Linear range } \\
\left(\mu \mathrm{g} \mathrm{mL} L^{-1}\right)\end{array}$} & \multirow[b]{2}{*}{ Regression equation } & \multirow[b]{2}{*}{$\begin{array}{l}\text { Correlation } \\
\text { coefficient }\end{array}$} & \multirow[b]{2}{*}{$\begin{array}{l}\text { Detection limit } \\
\left(\mu \mathrm{g} \mathrm{m}^{-1}\right)\end{array}$} & \multicolumn{2}{|c|}{$\begin{array}{l}\text { Intra-day RSD (\%) } \\
(n=5)\end{array}$} & \multicolumn{2}{|c|}{$\begin{array}{l}\text { Inter-day RSD (\%) } \\
(n=15)^{a}\end{array}$} \\
\hline & & & & & $\begin{array}{l}\text { Retention } \\
\text { time }\end{array}$ & Peak area & $\begin{array}{l}\text { Retention } \\
\text { time }\end{array}$ & Peak area \\
\hline DA & $0.05-4.00$ & $y=1.516 \times 10^{5} x+4.627 \times 10^{3}$ & 0.9903 & 0.01 & 0.5 & 2.1 & 2.0 & 4.0 \\
\hline
\end{tabular}

${ }^{a}$ The inter-day RSDs were determined by analyzing the sample based on five replicates on three consecutive days. 
Table 2 Recoveries of DA from certified shellfish samples with PCEC-LIF and HPLC-MS/MS ${ }^{a}$

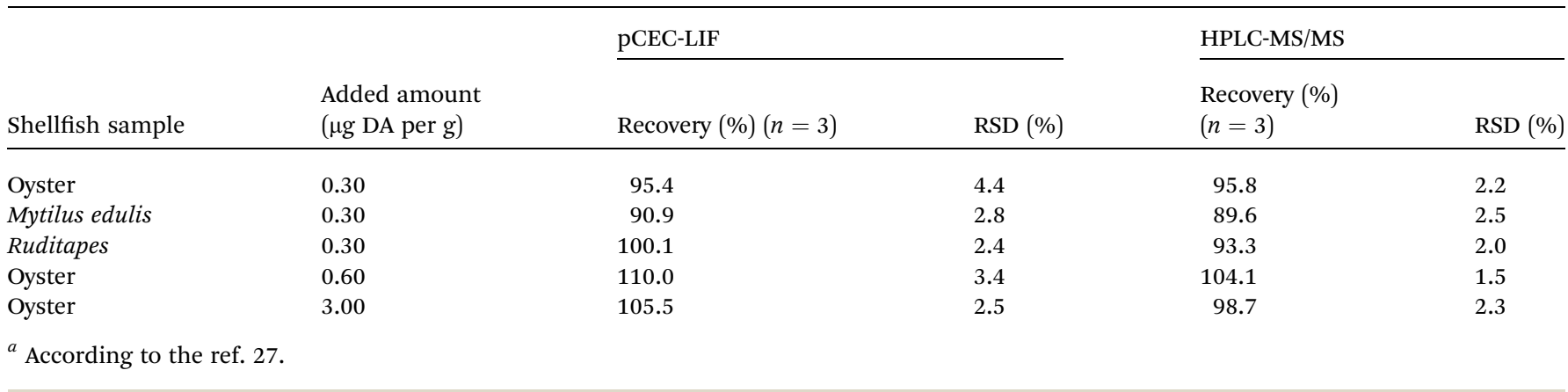

shellfish tissue), which was 130 times more sensitive than that of pCEC-UV method (LOD, $2.0 \mu \mathrm{g}$ DA per g). The sensitivity of this method would be better than that of CEC-PAD (the LOD was not provided in the reference, and it could be deduced as a level of $\mu \mathrm{g}$ DA per $\mathrm{g}$ like that of UV detector), better than that of CE-MS (70 ng DA per $\mathrm{mL}){ }^{28}$ and kept in a similar level to normal HPLC methods for DA analysis (LOD, 6-25 ng DA per g). ${ }^{7,8}$ Especially, in this pCEC method, a small amount of mobile phase was used with the flow in capillary column of $1.2 \mu \mathrm{L} \mathrm{min}{ }^{-1}$, which was only $1 / 800$ of that used in normal HPLC. The LOD of PCEC-LIF is far less than the guideline value in mussels ( $20 \mu \mathrm{g}$ DA per g, w.w. of shellfish tissue), and it is stable, low-reagent consumption and sufficiently sensitive to quantify DA in food safety monitoring.

3.3.2 Sample analysis. This analytical method was also applied to three kinds of shellfish samples (oyster, Mytilus edulis and ruditapes). The shellfish samples were prepared through spiking standard DA solutions into blank shellfish samples. Oyster, Mytilus edulis and ruditapes were extracted and subjected to SPE as described above, produced a pCEC chromatogram in which the DA-NBD derivative product was well resolved. The mean recoveries of certified shellfish samples spiked with standard DA at three concentrations ranged from $90.9 \%$ to $110 \%$ with an acceptable RSD (RSD $<4.4 \%$ ) (as shown in Table 2). Compared with the accepted authoritative HPLCMS/MS method, the detection results were similar and acceptable, which shows the developed pCEC-LIF method is reliable and suitable to quantify trace DA toxin.

\section{Conclusions}

A stable and sensitive pCEC-LIF hyphenated method for the analysis of trace DA in shellfishes was formed with low-reagent consumption, and the quantification for trace DA in shellfish seafoods was successfully achieved. Under the optimal conditions, a baseline separation with a high resolution of DA from shellfish matrices was gained within $12 \mathrm{~min}$. The pCEC-LIF method was robust and sensitive with the LOD of DA as low as $10 \mathrm{ng} \mathrm{mL} \mathrm{m}^{-1}(\mathrm{~S} / \mathrm{N}=3)$ (equivalent to $15 \mathrm{ng}$ DA per $\mathrm{g}$ ), which was more sensitive than most method fabricated with CEC-PAD and pCEC-UV. An extremely little amount of mobile phase was consumed economically with a flow of $1.2 \mu \mathrm{L} \mathrm{min}^{-1}$ in capillary column, which was only $1 / 800$ of that used in normal HPLC. A good repeatability was also obtained and RSD values (intraday, $n=3$ ) for retention time and peak area were less than $0.5 \%$ and $2.0 \%$, respectively. Applied to shellfish seafoods, the recoveries were obtained with satisfactory values in the range of 90.9$110 \%$. Compared with the accepted authoritative HPLC-MS/MS method, the detection results were similar and in a good level. The results indicated that pCEC-LIF hyphenated technology was robust and sensitive enough for the quantitative analysis of trace DA toxin in shellfish seafoods and hold promise for the application to food safety monitoring.

\section{Conflicts of interest}

There are no conflicts to declare.

\section{Acknowledgements}

This work was supported by National Natural Science Foundation of China (21377024), National Key Technologies R\&D Program of China (2014BAD13B01), and Scientific Research and develop project of Fujian province (2015Y0052, 2016Y4009 and 2017Y0056).

\section{References}

1 Y. He, A. Fekete, G. Chen, et al., J. Agric. Food Chem., 2010, 58, 11525.

2 V. L. Trainer, B. M. Hickey and R. A. Horner, Limnol. Oceanogr., 2002, 47(5), 1438.

3 P. Ajani, D. T. Harwood and S. Murray, Mar. Drugs, 2017, 15, 33.

4 J. Regueiro, G. Álvarez, A. Mauriz, et al., Food Chem., 2011, 127, 1884.

5 I. O. M. Chan, V. W. H. Tsang, K. K. Chu, et al., Anal. Chim. Acta, 2007, 583, 111.

6 M. Maroulis, I. Monemvasios and E. Vardaka, J. Chromatogr. B: Anal. Technol. Biomed. Life Sci., 2008, 876, 245.

7 K. J. James, M. Gillman, M. Lehane, et al., J. Chromatogr. A, 2000, 871, 1.

8 T. Jiang, L. Liu, Y. Li, et al., Chemosphere, 2017, 183, 80.

9 D. G. Beach, C. M. Walsh, P. Cantrell, et al., Rapid Commun. Mass Spectrom., 2016, 30, 2379. 
10 S. K. Zervou, C. Christophoridis, T. Kaloudis, et al., J. Hazard. Mater., 2017, 323, 56.

11 Y. Cheng, C. Guo, B. Zhao, et al., J. Sep. Sci., 2017, 40, 1583.

12 J. M. Leaó Martins, A. Gago-Martinez, E. DabekZlotorzynska, et al., J. Sep. Sci., 2002, 25, 342.

13 (a) A. Gago-Martínez, N. Pinéiro, E. C. Aguete, et al., J. Chromatogr., A, 2003, 992, 159; (b) T. Eimer, K. K. Unger and T. Frensenius Tsuda, Anal. Chem., 1995, 352, 649.

14 (a) Q. Ru, G. Luo, Y. Fu, et al., J. Chromatogr. A, 2001, 924, 331; (b) F. Ye, Z. Xie, X. Wu, et al., Talanta, 2006, 69, 97.

15 J. Wang, F. Wu and R. Xia, J. Chromatogr. A, 2016, 1449, 100. 16 Y. Huo and W. T. Kok, Electrophoresis, 2008, 29, 80.

17 X. Lin, Y. Li, D. Xu, et al., Analyst, 2013, 138, 635.

18 Z. Liang, J. C. Duan, L. H. Zhang, et al., Anal. Chem., 2004, 76, 6935.

19 J. Wang, F. Wu, R. Xia, et al., J. Chromatogr. A, 2016, 1449, 100.
20 X. Wang, Y. Zheng, C. Zhang, et al., J. Chromatogr. A, 2012, 1239, 56.

21 W. Wu, X. Wu, X. Lin, et al., J. Sep. Sci., 2009, 32, 2117.

22 C. Liu, Q. Deng, G. Fang, et al., Anal. Biochem., 2017, 530, 50.

23 C. Yan, R. Dadoo, H. Zhao, et al., Anal. Chem., 1995, 67(13), 2026.

24 Q. Wan, X. Ru, X. Wang, et al., Chin. J. Anal. Chem., 2015, 43(7), 1063.

25 Y. Wu, J. Lin, Q. Wu, et al., J. Pharm. Biomed. Anal., 2010, 53, 1324.

26 S. Štěpánová and V. Kašička, Anal. Chim. Acta, 2016, 933, 23.

27 W. Zhang, M. Lin, P. Tong, et al., J. Chromatogr. A, 2016, 1443, 54 .

28 C. Bignardi, A. Cavazza and C. Corradini, Electrophoresis, 2012, 33, 2382. 